\title{
DRAFT
}

\section{Chamber Dynamic Research with Pulsed Power}

\author{
Robert R. Peterson ${ }^{3}$ \\ C. L. Olson, T.J. Renk, G.E. Rochau, and M.A. Sweeney ${ }^{2}$ \\ ${ }^{1}$ University of Wisconsin-Madison \\ ${ }^{2}$ Sandia National Laboratories-Albuquerque \\ March 8, 2000
}

\begin{abstract}
.
In Inertial Fusion Energy (IFE), Target Chamber Dynamics (TCD) is an integral part of the target chamber design and performance. TCD includes target output, deposition of target $x$-rays, ions and neutrons in target chamber gases and structures, vaporization and melting of target chamber materials, radiation-hydrodynamics in target chamber vapors and gases, and chamber conditions at the time of target and beam injections. Pulsed power provides a unique environment for IFE-TCD validation experiments in two important ways: they do not require the very clean conditions which lasers need and they currently provide large $\mathrm{x}$-ray and ion energies.
\end{abstract}

PASC Classification Codes: $52.25 . \mathrm{Nr}, 52.58 . \mathrm{Ns}, 52.40 . \mathrm{Db}, 81.70 . \mathrm{Bt}$,
$44.40 .+\mathrm{a}, 44.40 .+\mathrm{f}$

Keywords: Inertial Fusion Energy, Pulsed Power, Target Chambers, Computer Code Validation

Primary Author: Robert R. Peterson

Fusion Technology Institute

University of Wisconsin

1500 Engineering Drive

Madison, WI 53706 USA

FAX: (608) 263-4499; Phone: (608) 263-5646

E-Mail: rpeters@facstaff.wisc.edu

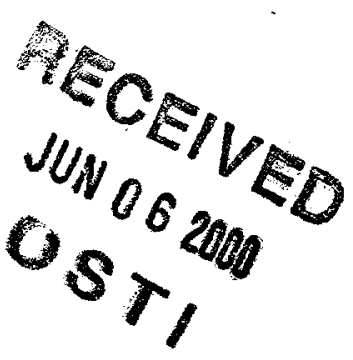

Sandia is a multiprogram laboratory operated by Sandia Corporation, a

Lockheed Martin Company, for the

United States Department of Energy

under contract DE-AC04-94AL85000. 


\section{DISCLAIMER}

This report was prepared as an account of work sponsored by an agency of the United States Government. Neither the United States Government nor any agency thereof, nor any of their employees, make any warranty, express or implied, or assumes any legal liability or responsibility for the accuracy, completeness, or usefulness of any information, apparatus, product, or process disclosed, or represents that its use would not infringe privately owned rights. Reference herein to any specific commercial product, process, or service by trade name, trademark, manufacturer, or otherwise does not necessarily constitute or imply its endorsement, recommendation, or favoring by the United States Government or any agency thereof. The views and opinions of authors expressed herein do not necessarily state or reflect those of the United States Government or any agency thereof. 


\section{DISCLAIMER}

\section{Portions of this document may be illegible in electronic image products. Images are produced from the best available original document.}




\section{Introduction}

In Inertial Fusion Energy (IFE), Target Chamber Dynamics (TCD) is an integral part of the target chamber design and performance. TCD includes target output, deposition of target x-rays, ions and neutrons in target chamber gases and structures, vaporization and melting of target chamber materials, radiation-hydrodynamics in target chamber vapors and gases, and chamber conditions at the time of target and beam injections. An understanding of TCD is required to design a target chamber that is economically viable and does not pose a threat to safety or the environment. Computer codes have been developed that model TCD phenomena [1]. BUCKY [2], written at the University of Wisconsin, is one example of such a code. BUCKY is a 1-D Lagrangian radiation-hydrodynamics computer code that includes realistic atomic physics, multigroup radiation diffusion, $\mathrm{x}$-ray and ion deposition physics, and vaporization, melting and recondensation physics. Validation of codes with small but relevant experiments is critical because full-scale experiments will only be possible with ignited targets.

Pulsed power provides a unique environment for IFE-TCD validation experiments in two important ways: they do not require the very clean conditions which lasers need and they currently provide large $\mathrm{x}$-ray and ion energies. Z-pinch experiments on the $\mathrm{Z}$ accelerator at Sandia National Laboratories (SNL) presently can produce approximately $2 \mathrm{MJ}$ of $>100 \mathrm{eV}$ blackbody $\mathrm{x}$-rays in a several ns pulse. The spectrum is colder than what is expected from IFE targets, but the achievable fluences and pulse widths are IFE relevant. $X$-ray vaporization and chamber gas radiation hydrodynamics can be studied with $\mathrm{Z}$ as an $\mathrm{x}$-ray source. These $\mathrm{x}$ rays could produce high energy density plasmas that mimic phenomena in target explosions that lead to target emissions. In addition, the RHEPP-1 accelerator at SNL can produce up to $15 \mathrm{~J} / \mathrm{cm}^{2}$ of several $100 \mathrm{keV}$ ions of many species with IFE-relevant pulse widths, which could be used to simulate target ion stopping in vapors and gases, and ion melting and vaporization of wall materials.

\section{IFE Target Chamber Dynamics}

TCD is the integrated study of everything in the IFE target chamber inside the surviving structure. This TCD analysis is an essential part of IFE target chamber design, and therefore critical to the development of IFE as an energy source. Target chamber dynamics analysis also leads to chamber designs where chamber walls can survive an adequate length of time, where the repetition rate is acceptable, where the chamber does not pose a threat to safety or the environment, and where the driver beams can propagate and targets can be injected. The TCD analysis includes the following:

- target output characteristics,

- deposition of target emissions in target chamber gases, vapors and structures,

- disassembly and re-assembly of liquid jet structures,

- vaporization and re-condensation of liquid and solid target chamber materials,

- radiation-hydrodynamics of target chamber fill gases and vaporized material,

- chamber conditions at time of beam injection,

- target heating during injection.

\section{DRAFT}




\section{DRAFT}

The chamber design also has links to other systems, including the target injector, driver beam final focusing optics, and the structural wall. Analyses of these systems need input from TCD calculations. These include:

- laser or ion beam transport through the target chamber,

- mechanical response of surviving target chamber structures,

- thermal response of surviving target chamber structures,

- tritium retention in surviving target chamber structures,

- neutron activation in surviving target chamber structures.

The analysis of the TCD is strongly driven by the target output and is sensitive to energy partition between photons, neutrons and ions and their spectra. When an IFE target ignites and burns, about $80 \%$ of its fusion energy is released as $14 \mathrm{MeV}$ neutrons. The density-radius product of the fuel is about $3 \mathrm{gm} / \mathrm{cm}^{2}$, so the fuel itself re-absorbs about $15 \%$ of the neutron energy and softens the neutron spectrum. The ionic fusion products, mostly ${ }^{4} \mathrm{He}$ but some ${ }^{3} \mathrm{He},{ }^{3} \mathrm{H}$, and ${ }^{1} \mathrm{H}$ and other minor contributors, are almost entirely stopped in the dense fuel, the so-called bootstrap heating effect. About $30 \%$ of the DT fuel typically burns during a target explosion. The fuel reaches $50 \mathrm{keV}$ or more during burn, becoming fully ionized so it produces bremsstrahlung photons, but very few bound-bound or bound-free photons. Because bremsstrahlung emission from hydrogen isotopes is relatively weak, only a few percent of the fuel capsule yield is in photons. The remaining $20-25 \%$ of the capsule yield is an expanding flow of energetic ions that comprise the capsule. The whole capsule, including the ablator is accelerated outward in the target explosion. For direct-drive laser fusion targets, the capsule is the entire target. For current indirect-drive heavy and light ion targets and for z-pinch IFE, the fuel capsule is enclosed in a massive high atomic number hohlraum. The neutrons are unaffected by the hohlraum, but this very high velocity expanding capsule plasma collides with the hohlraum imparting its energy and momentum to the hohlraum. The much more massive hohlraum is raised to temperatures of hundreds of $\mathrm{eV}$, thus converting the highly directed kinetic energy of the capsule ions to thermal $\mathrm{x}$ rays that are radiated by the more slowly expanding hohlraum plasma.

Radiation-hydrodynamics modeling in IFE target chambers is important to the analysis of gas-protected, thin-liquid film and thick-liquid wall target chamber designs. For any reasonably sized target chamber, the intense non-neutronic emission released from both direct- and indirectdrive targets heats the material absorbing that energy to a temperature where radiative heat transfer is important. In liquid designs with a low-density vapor in the chamber, the vapor generated by the absorption of target energy will radiate and cause additional vaporization. Self-shielding of the liquid by its vapor is important in determining the total mass of liquid vaporized. In gas-protected concepts the gas will radiate to the first wall, which must avoid erosion through vaporization, melting and fracture.

Typical IFE target chamber X-ray parameters are shown in Table 1 for HIBALL[3], CASCADE[4], HYLIFE-II[5], LIBRA-SP[6] and OSIRIS[7]. These are all indirect-drive power plant concepts where the $\mathrm{x}$-ray output is dominant. With the exception of HYLIFE-II where the first surface is very close to the target, the x-ray fluence per shot is in the range of 25 to $85 \mathrm{~J} / \mathrm{cm}^{2}$. Alternatively, the SOMBRERO [8] direct-drive laser fusion target chamber would have $4.5 \mathrm{~J} / \mathrm{cm}^{2}$ 


\section{DRAFT}

of $\mathrm{x}$-rays on its graphite first wall if the Xenon fill gas were not present. However, SOMBRERO would experience ion fluences on its graphite wall of $15.8 \mathrm{~J} / \mathrm{cm}^{2}$ and lower but still worrisome fluences on final optics.

\section{Computer Simulation Methods}

A few codes exist to model TCD, one being BUCKY. The BUCKY 1-D radiationhydrodynamics code models many aspects of TCD. BUCKY, whose features are listed below, has been developed at the University of Wisconsin over the past 25 years. It has been benchmarked in comparison with many experiments on lasers, shock-tubes and pulsed power machines. It has been used to do ICF target design, and calculate target output, wire-array implosions, and target chamber dynamics. Most importantly for this discussion, BUCKY calculates the response on material to intense $\mathrm{x}$-rays, including vaporization and melting, vapor motion and shocks in the remaining solid material.

- 1-D Lagrangian MHD (spherical, cylindrical or slab).

- Thermal conduction with diffusion.

- Applied electrical current with magnetic field and pressure calculation.

- Radiation transport with multi-group flux-limited diffusion, method of short characteristics, and variable Eddington factor.

- Non-LTE CRE line transport.

- Opacities and equations of state from EOSOPA or SESAME.

- Equilibrium electrical conductivities

- Thermonuclear burn (DT,DD, $\mathrm{DHe}^{3}$ ) with in-flight reactions.

- Fusion product transport; time-dependent charged particle tracking, neutron energy deposition.

- $\quad$ Applied energy sources: time and energy dependent ions, electrons, and $x$-rays.

- Moderate energy density physics: melting, vaporization, and thermal conduction in solids and liquids.

- Benchmarking: $\mathrm{x}$-ray burn-through and shock experiments on Nova and Omega, $\mathrm{x}$-ray vaporization, RHEPP melting and vaporization, PBFA-II $\mathrm{K}_{\alpha}$ emission, ...

- Platforms: UNIX, PC, MAC

One important aspect of all TCD experiments is the validation of these computer codes. There are many complex physics issues that are modeled. The radiations transport methods used have finite ranges of validity. Most are fluid codes and sometimes the materials will either fall below a pressure of a few Mbar where strength of materials becomes an issue, or will reach a low enough density that gas particle are low longer in equilibrium with each other. The experiments suggested below will be useful in addressing these issues and benchmarking the codes. 


\section{DRAFT}

\section{Pulse Power Facilities}

The $Z$ and Saturn z-pinch facilities can supply IFE target chamber relevant $x$-ray fluences, pulse widths and spectra [9], while RHEPP can do the same for ions. Many of the issues discussed above can be studied experimentally on these pulsed-power facilities. Achievable x-ray fluences are shown in table 2 for $Z$. Saturn, which produces about $0.5 \mathrm{MJ}$ of soft $\mathrm{x}$-rays would require sample to be closer to the $x$-ray source than $Z$ would, but high fluences may still be reached. The distance between the $x$-ray source and the sample is important because the z-pinch assembly is a source of debris as well as $\mathrm{x}$-rays. The debris consists on ions and larger chunks of material than can damage the sample and complicate the interpretation of experiments. With distant, the debris becomes separated in time from the $\mathrm{x}$-rays and allows for mitigation.

In comparison, the NIF will also allow for relevant $\mathrm{x}$-ray fluences, spectra and pulse widths. Parameters expected for NIF are shown in Table 3. For the not ignited NIF, it is assumed $1.4 \mathrm{MJ}$ of absorbed laser energy leads to $1.0 \mathrm{MJ}$ of $\mathrm{x}$-rays. As laser beams are turned on with $\mathrm{NIF}$, the value will start much smaller and rise to approximately this level when it is fully constructed. If a fusion target is used on NIF, the laser-generated $x$-rays implode and ignite an ICF capsule, which is assumed here to create $20 \mathrm{MJ}$ of fusion yield. About $20 \%$, or $4 \mathrm{MJ}$, of this yield would be released as $\mathrm{x}$-rays. So, the NIF and $\mathrm{Z}$ could generate close to the same fluences of $\mathrm{x}$-rays, though the spectra may be different.

As $\mathrm{x}$-ray generators $\mathrm{Z}$ and Saturn have some advantages and disadvantages compared with NIF. First of all, $Z$ and Saturn exist now, while NIF will not begin operation for a few years and will not reach its full laser energy or ignition of ICF targets for several years after that. The largest currently existing available laser facility, Omega, might now create about $15 \mathrm{~kJ}$ of $\mathrm{x}$-rays. Another advantage of $Z$ and Saturn is that they do not need to limit the production of large amounts of debris since the z-pinch assembly is a larger source of debris than the experiments. NIF will have to limit the amount of debris produced in a shot to prevent the excessive damage to or coating of laser debris shields. However the debris produced on $Z$ and Saturn make experiments more complicated, so the low debris mass on NIF could be seen as an advantage as long as the experiment did not generate much debris itself. The NIF laser will be able to divert several of its to drive $\mathrm{x}$-ray backlighters for diagnostics of experiments, while $\mathrm{Z}$ will soon have a single backlighter laser and Saturn has none.

The RHEPP facility produces high rep-rate pulses of intense ions beams. The only constraint on experiments (aside from the usual toxicity and radioactivity limits) is that the ion diode needs to be in a vacuum. Diagnostics for ion beam parameters are currently available. Experimental sample diagnostics, such as VISAR's, laser reflectometry for melt duration, and lasers for vapor plume diagnostics are easily done. X-ray diagnostics would have to be developed for some experiments.

\section{Experimental Studies of IFE Chamber Dynamics}

A number of experiments are under consideration of on pulse power machines to study IFE target phenomena. These include the areas of target output, response of materials to intense $x$-rays, 


\section{DRAFT}

target chamber blast waves, and response of materials to intense ions debris. These represent several issues critical to TCD. These are also all phenomena that can be modeled with codes like BUCKY.

The non-neutronic output emitted by direct drive targets is primarily in ionic debris. In the SOMBRERO study, the target chamber size and fill gas species and density are dictated by output ion spectra. Experiments are planed on $Z$ or Saturn to simulate the break-up of the target ablator into ion debris. In a direct-drive IFE target, the ablator is accelerated to a very high $(-3000 \mathrm{~km} / \mathrm{s})$ velocity by the explosion of the capsule. Carbon atoms in a plastic ablator at this velocity would have a particle kinetic energy of $560 \mathrm{keV}$. Some direct drive targets designs call for Gold to be added to the ablator, which would have a particle energy of $9.2 \mathrm{MeV}$. But, in fact, the heavier particles may be moving more slowly than the hydrogen atoms. In the experiments, a foil of ablator material would be irradiated with intense $z$-pinch $\mathrm{x}$-rays and rapidly accelerated to as high a velocity as possible. A mass spectrometer or CR39 emulsion would record the ion energy, which would be compared with code predictions of the ion energies. As a second type of target output experiment, the ions from the foil would collide with a simulated hohlraum case (a Gold or Lead foil) and create a stagnant plasma like what occurs inside the case of an ignited IFE indirect-drive target. The $\mathrm{x}$-ray spectrum emitted from this plasma would be recorded and compared with code calculations.

The response of materials to intense $\mathrm{x}$-rays is clearly a class of experiments than can be done on $\mathrm{Z}$ and Saturn. All of the materials and fluences given in Table 1 are of interest. One question to be resolved is the fidelity of $z$ and Saturn in simulating the response of materials to IFE direct- and indirect-drive target $x$-rays. Figures 1 and 2 try to address this. Figure 1 shows the results of a BUCKY calculation of the response of a piece of stainless steel to $100 \mathrm{~J} / \mathrm{cm}^{2}$ of $\mathrm{x}$-rays from a Titanium wire array pinch. Using the expected spectrum and pulse width ( 13 ns FWHM) a shock of about $1 \mathrm{Mbar}$ is launched into the steel. Figure 1 shows the density profiles for such an experiment. Figure 2 shows the results of a BUCKY calculation for a piece of steel irradiated by $100 \mathrm{~J} / \mathrm{cm}^{2}$ of $\mathrm{x}$-rays, with the spectrum and pulse width $(\sim 3 \mathrm{~ns}$ FWHM $)$ calculated for the LIBRASP target. One can steel that the compression and speed of the shock in the solid material is very close in the two cases. It is interesting to note that the pressures of the propagating shock is about 1 $\mathrm{Mbar}$, where the fluid approximation in BUCKY needs to be corrected for strength of material effects. There are some differences in the blow-off plasma, perhaps due to the pulse widths. In these experiments, masking part of a sample from the $\mathrm{x}$-rays and then performing post-shot profilometry would study vaporization and melting. Electron microscopy of samples would identify melt layers and changes in microstructure. The re-coil shock and impulse of the sample would be measured with diagnostics on the back of the sample. The dynamics of the vapor could be probed with $\mathrm{x}$-ray radiography or laser shadowgraphy. After sufficient experimentation on material samples, larger scale IFE chamber components could be tested.

Blast waves are another important aspect of TCD that can be studied on $\mathrm{Z}$ and Saturn. When a gas or vapor is heated to a temperature high enough that radiation transport is important, the opacity of the gas is important to the TCD. This occurs in gas protected target chambers such as SOMBRERO, where the target ions and $x$-rays are deposited in the gas and the re-radiation rate to the target chamber walls determines the target chamber design. Liquid wall target chambers also 


\section{DRAFT}

have similar phenomena when the target $\mathrm{x}$-rays vaporize material and the ions further heat it. In both cases, the gas or vapor heats to temperatures of 5 to $100 \mathrm{eV}$. It is very difficult to know the opacity of gases below about $10 \mathrm{eV}$. They are calculated but the validity of these calculations needs to be tested. Figure 3 shows how sensitive the radiation reaching the SOMBRERO wall is to the opacity. Here BUCKY calculations have been performed using various multipliers on the Planck opacity. In this case, the fill gas is optically thin, so the rate that radiation reached the chamber walls is dominated by the emission of radiation, which is governed by the Planck opacity. The greater the opacity is, the better the gas emits and the higher the radiant power. There are two types of experiments on $\mathrm{Z}$ and Saturn that could address this issue. Creating a plasma with $\mathrm{x}$-rays at the desired temperature and density and then measuring its opacity through spectral absorption could directly measure the opacity. Another method would create a blast wave in a gas or foam and measure it's properties for comparison with code calculations using calculated opacities. Both are required to fully understand this issue.

The response of materials to intense ions is the final type of experiment we will mention here. Ion deposition in target chamber fill gases in gas-protected chambers drives the formation of blast waves. Also, ion heating of $\mathrm{x}$-ray produced vapor is important to blast waves in liquid wall target chambers. Ion driven blast wave experiments could be done on RHEPP, where the gas is replaces by a foam or a vapor created on a preceding shot. Ion damage to solids and liquids is also an issue. For example, ion damage to final optics in laser fusion power plant concepts might be an issue. Figure 4 shows the results of a set of melt-duration experiments done on RHEPP, with comparisons to BUCKY simulations. Here a piece of pure silicon was irradiated with a beam of Nitrogen and Hydrogen ions at several hundred to more than $1000 \mathrm{keV}$ and fluences up to $3 \mathrm{~J} / \mathrm{cm}^{2}$. The calculated melt depth is also shown. Silicon has the property that the laser reflectivity is very different for the solid and liquid, so the duration of the melt layer can be measured and compared with calculations. The agreement with but is not perfect but is encouraging.

\section{Conclusions}

Several types of experiments have been suggested that are important to IFE TCD than could be done on pulsed-power facilities. These include,

- Target ion and $\mathrm{x}$-ray output experiments,

- Response of materials to intense $x$-rays,

- X-ray driven blast wave experiments, and

- Response of materials to intense ion beams.

$\mathrm{Z}$ and Saturn are robust facilities that exist today with improving diagnostics. The NIF laser will also be useful for doing some of these experiments when it is available. The RHEPP facility is useful for ion beam experiments. All of these experiments are critical to validating TCD computer codes and understand the phenomena. For IFE to progress as an energy option these issues must be faced.

\section{Acknowledgement}

This work was supported by the US Department of Energy and Sandia National Laboratories. The authors wish to acknowledge useful discussions with Prof. Per Peterson and Dr. Mark Tillack. 


\section{DRAFT}

\section{References}

1. G.A. Moses, R.R. Peterson, and J.J. MacFarlane, "Analysis and Experiments in Support of ICF Reactor Concepts" Physics of Fluids B 3, 2324 (August, 1991).

2. R.R. Peterson, et al., "The BUCKY and ZEUS-2D Computer Codes for Simulating High Energy Density ICF Plasmas," Fusion Technology 30, 783, (1996).

3. B. Badger, et al., "HIBALL - A Conceptual Heavy Ion Beam Driven Fusion Reactor Study," University of Wisconsin Fusion Technology Institute Report UWFDM- 450 (September 1981).

4. CASCADE[3], G. Kessler, G.L. Kulcinski, and R.R. Peterson, "ICF Reactors - Conceptual Designs," in Nuclear Fusion by Inertial Confinement, A Comprehensive Treatise, edited by G. Velarde (CRC Press, 1992) p. 673.

5. R.W. Moir, et al., "HYLIFE-II Progress Report," Lawrence Livermore National Laboratory Report UCID-21816 (December 1991).

6. G.L. Kulcinski, et al., "LIBRA-SP, A Commercial Fusion Reactor Based on Near Term Technology," Fusion Technology 30, 1641 (1996).

7. W.R. Meier, et al., "OSIRIS and SOMBRERO Inertial Fusion Power Plant Designs," W.J. Shafer and Associates Report WJSA-91-01 (March 1992).

8. I.N. Sviatoslavsky, "A KrF Laser Driven Inertial Fusion Reactor " SOMBRERO"," Fusion Technology 21, 1470 (1992).

9. D.D. Ryutov, M.S. Derzon, and M.K. Matzen, "The Physics of Fast Z Pinches," Rev. Mod. Phys. 72, 167 (2000). 


\section{DRAFT}

\section{Figure Captions}

Figure 1. Mass density profiles at various times calculated in stainless steel with BUCKY. 100 $\mathrm{J} / \mathrm{cm}^{2}$ of $\mathrm{X}$-rays with the spectrum and pulse width from $\mathrm{Z}$ shot 302 .

Figure 2. Mass density profiles at various times calculated in stainless steel with BUCKY. 100 $\mathrm{J} / \mathrm{cm}^{2}$ of $\mathrm{x}$-rays with the spectrum and pulse width calculated for the LIBRA-SP target.

Figure 3. Radiant heat flux on SOMBRERO first wall versus time for a variety of multipliers on the Planck opacity of Xenon gas. Calculations with BUCKY for a $400 \mathrm{MJ}$ direct drive target and a $650 \mathrm{~cm}$ radius chamber filled with 0.5 Torr of Xenon.

Figure 4. Ion melting of Silicon. RHEPP experiments and BUCKY simulations. 


\section{DRAFT}

Table 1 X-ray Environment for Some IFE Target Chambers.

\begin{tabular}{|c|c|c|c|c|c|}
\hline Parameter & HIBALL & CASCADE & HYLIFE-II & LIBRA-SP & OSIRIS \\
\hline $\begin{array}{c}\text { X-ray Energy per } \\
\text { shot }(\mathrm{MJ})\end{array}$ & 89.5 & 75 & 56 & 168.1 & 71.9 \\
\hline $\begin{array}{c}\text { Distance from X- } \\
\text { ray Source }(\mathrm{cm})\end{array}$ & 500 & 400 & 50 & 400 & 350 \\
\hline $\begin{array}{c}\mathrm{X} \text {-ray Fluence per } \\
\text { shot }\left(\mathrm{J} / \mathrm{cm}^{2}\right)\end{array}$ & 28.5 & 37.3 & 1800 & 83.6 & 46.7 \\
\hline $\mathrm{T}_{\mathrm{BB}}(\mathrm{eV})$ & 450 & 450 & $100-400$ & 450 & 450 \\
\hline Material & $\mathrm{Pb}_{83} \mathrm{Li}_{17}$ & Graphite & Flibe & $\mathrm{Pb}_{83} \mathrm{Li}_{17}$ & Flibe \\
\hline
\end{tabular}

Table 2. X-ray Environment for Z

\begin{tabular}{|c|c|c|c|c|}
\hline Parameter & \multicolumn{5}{|c|}{ Z (Z-PINCH ONLY) } \\
\hline X-ray Energy per shot (MJ) & \multicolumn{4}{|c|}{2} \\
\hline Distance from X-ray Source $(\mathrm{cm})$ & 399 & 72.8 & 39.9 & 7.28 \\
\hline X-ray Fluence per shot $\left(\mathrm{J} / \mathrm{cm}^{2}\right)$ & 1.0 & 30 & 100 & 3000 \\
\hline $\mathrm{T}_{\mathrm{BB}}(\mathrm{eV})$ & \multicolumn{5}{|c|}{200} \\
\hline
\end{tabular}

Table 3. X-ray Damage Parameters for NIF

\begin{tabular}{|c|c|c|c|c|c|c|c|c|}
\hline Parameter & \multicolumn{3}{|c|}{ NIF (20 MJ Target) } & \multicolumn{3}{c|}{ NIF (1.4 MJ laser only) } \\
\hline $\begin{array}{c}\text { X-ray Energy per } \\
\text { shot (MJ) }\end{array}$ & \multicolumn{3}{|c|}{4} & \multicolumn{3}{c|}{1} \\
\hline $\begin{array}{c}\text { Distance from X-ray } \\
\text { Source (cm) }\end{array}$ & 564 & 103 & 56.4 & 10.3 & 282 & 51.5 & 28.2 & 5.15 \\
\hline $\begin{array}{c}\text { X-ray Fluence per } \\
\left.\text { shot (J/cm }{ }^{2}\right)\end{array}$ & 1.0 & 30 & 100 & 3000 & 1.0 & 30 & 100 & 3000 \\
\hline $\mathrm{T}_{\mathrm{BB}}(\mathrm{eV})$ & \multicolumn{6}{|c|}{400} & \multicolumn{4}{|c|}{$100-400$} \\
\hline
\end{tabular}




\section{DRAFT}

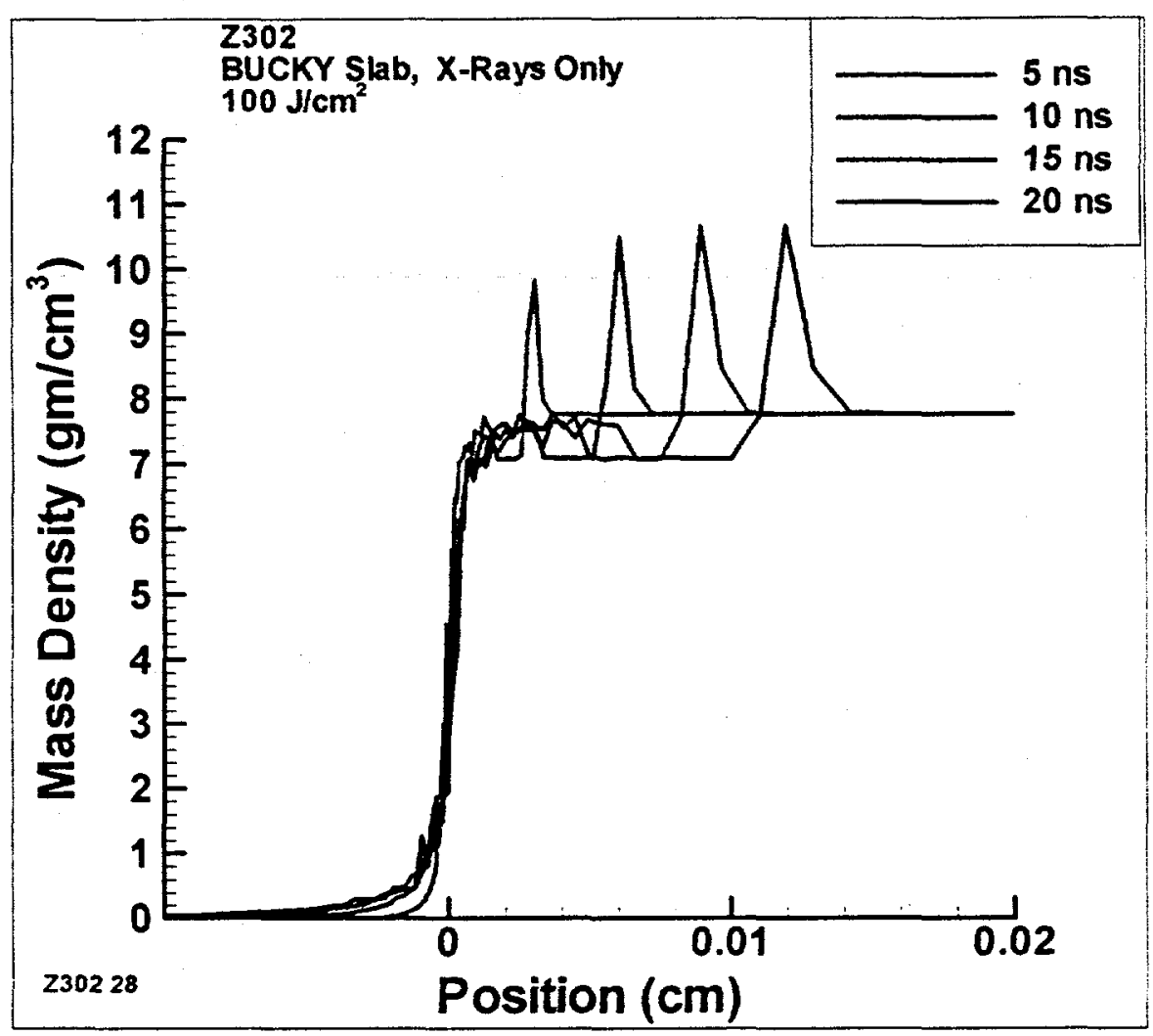

Figure 1. Mass density profiles at various times calculated in stainless steel with BUCKY. 100 $\mathrm{J} / \mathrm{cm}^{2}$ of $\mathrm{x}$-rays with the spectrum and pulse width from $\mathrm{Z}$ shot 302 . 


\section{DRAFT}

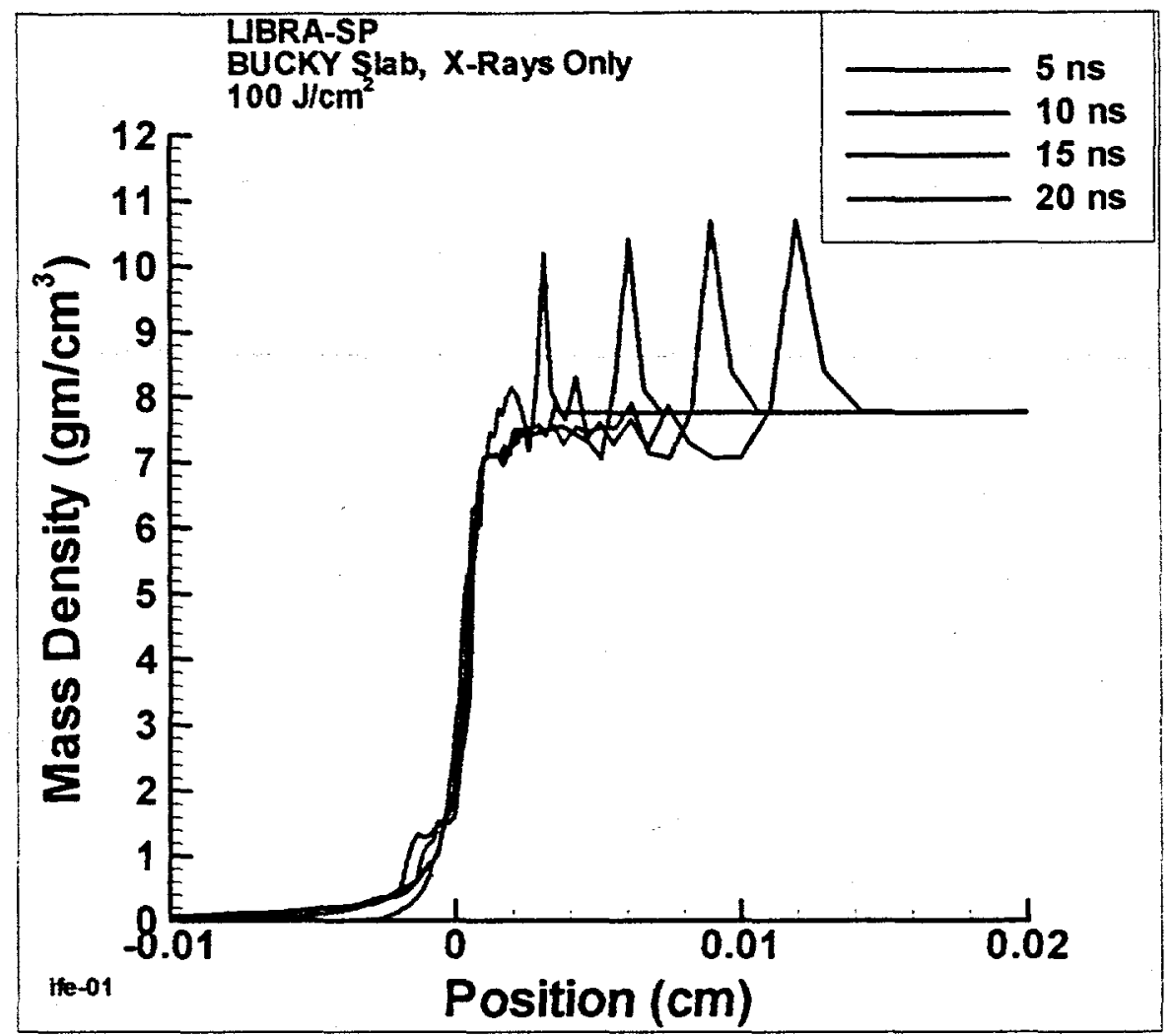

Figure 2. Mass density profiles at various times calculated in stainless steel with BUCKY. 100 $\mathrm{J} / \mathrm{cm}^{2}$ of $\mathrm{x}$-rays with the spectrum and pulse width calculated for the LIBRA-SP target. 


\section{DRAFT}

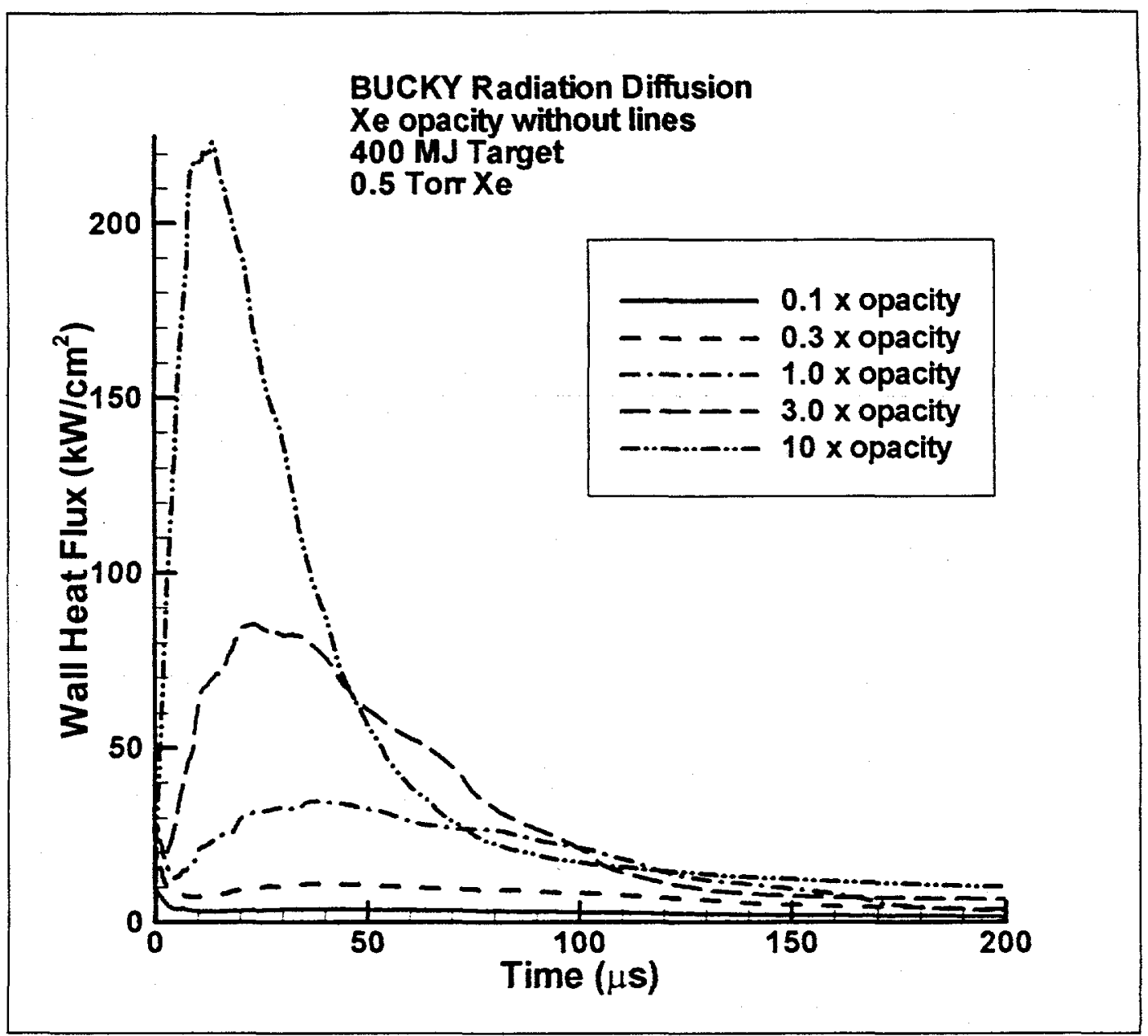

Figure 3. Radiant heat flux on SOMBRERO first wall versus time for a variety of multipliers on the Planck opacity of Xenon gas. Calculations with BUCKY for a $400 \mathrm{MJ}$ direct drive target and a $650 \mathrm{~cm}$ radius chamber filled with 0.5 Torr of Xenon. 


\section{DRAFT}

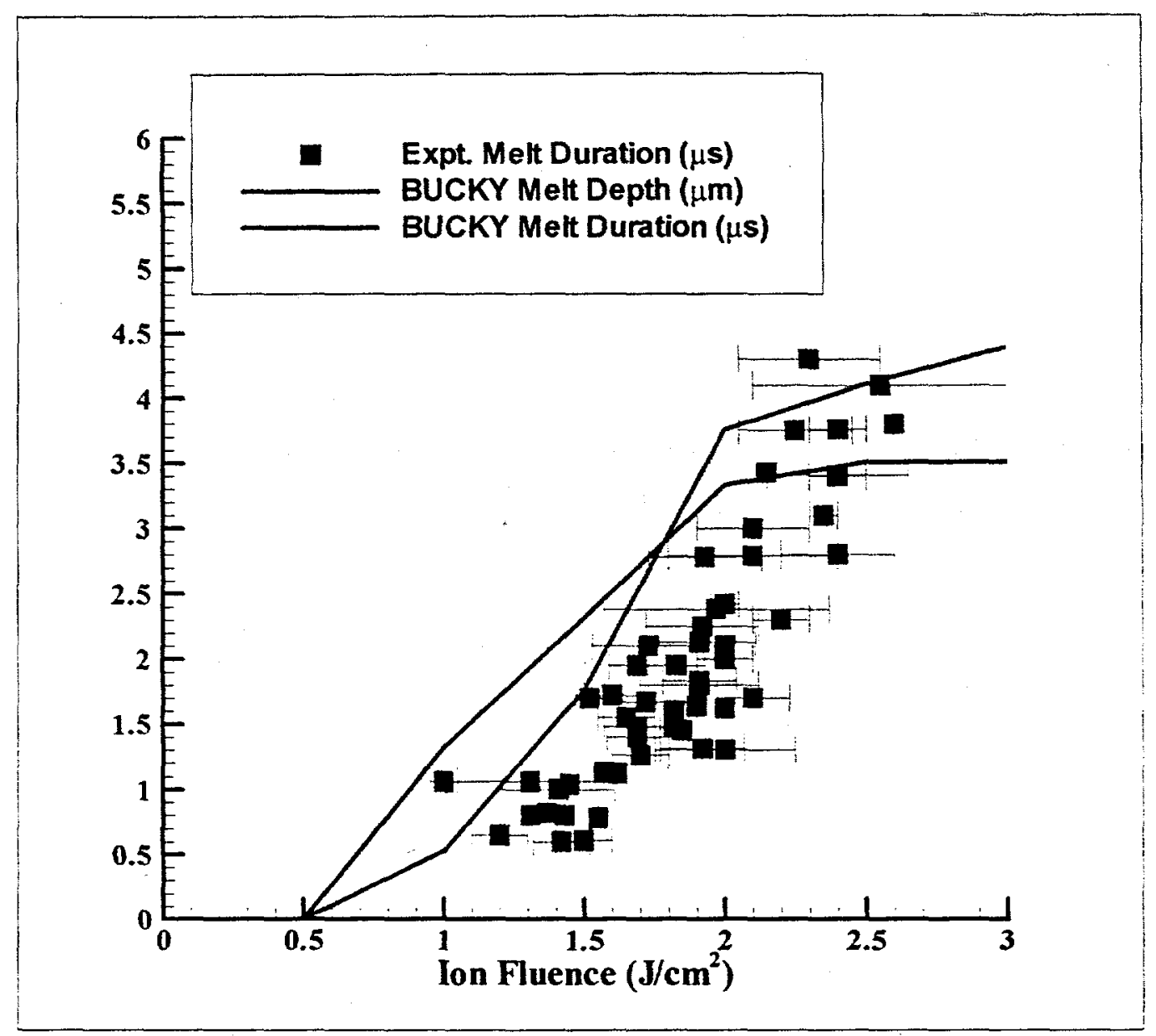

Figure 4. Ion melting of Silicon. RHEPP experiments and BUCKY simulations. 